\section{P58 INDICES OF TB RISK CAN HELP STRATIFY RECENT IMIMIGRANTS REGISTERING WITH A GP FOR TARGETED SCREENING}

doi:10.1136/thoraxjnl-2011-201054c.58

R K Panchal, P Haldar, G Woltmann. Glenfield Hospital, University Hospitals of Leicester, Institute for Lung Health (ILH), Leicester, UK

Introduction The burden of tuberculosis (TB) in the UK may only be lowered significantly by identification and treatment of latent infection with $M$ tuberculosis (LTBI) in recent immigrants from moderate (150-499/100 000) and high prevalence $(500+/ 100000)$ regions of disease. An approach that focuses immigrant capture to a limited number of GP practices is feasible in our region as the distribution of registrations and TB cases by GP practice is heavily skewed. However, strategies for identifying the most appropriate practices and immigrant subgroups for targeted screening are not known.

Aims To evaluate indices of TB risk that may inform targeted screening strategies for newly registering immigrants to Leicestershire (Exeter/Flag-4).

Methods A retrospective analysis was performed of all Flag 4 immigrant registrations between 2000 and 2010 and collated with data for all TB notifications over the same period. The top 10 practices defined by number of registrations (10R), number of TB cases $(10 T B)$ and a weighted index $[\mathrm{WI}=(\mathrm{TB}$ cases/immigrant registrations) $\times$ TB cases] were identified and compared. Logistic regression was performed to model independent predictors of $\mathrm{TB}$ events. TB risk for specified immigrant subgroups was estimated using Kaplan-Meier analysis and pair-wise comparisons of risk computed as the rate ratio $(95 \% \mathrm{CI})$.

Results $564 \mathrm{~TB}$ cases were recorded in 34764 registered immigrants at 148 practices. Independent predictors of TB risk were immigrant age at registration and gender and deprivation index of the GP practice locality. Compared with registration at a non-top 10 practice, the corresponding rate ratios for $\mathrm{TB}$ after 5 years at a top 10 practice were 1.32 (95\% CI 1.1 to 1.57 ) for 10R; 1.72 (95\% CI 1.44 to 2.1 ) for $10 \mathrm{~TB}$ and 1.79 (95\% CI 1.5 to 2.14 ) for 10WI. Compared with the unselected registering immigrant population, the 5 and 10 year $\mathrm{TB}$ rates in 10WI practices were significantly higher for immigrants aged 16-35 years but not older adults $>35$ years (Abstract P58 table 1).

\section{Abstract P58 Table 1}

\begin{tabular}{|c|c|c|c|c|}
\hline \multirow[b]{3}{*}{$\begin{array}{l}\text { TB rate/100 } 000 \\
\text { person years }\end{array}$} & \multicolumn{4}{|l|}{ Age groups } \\
\hline & \multicolumn{2}{|l|}{$16-35$} & \multicolumn{2}{|l|}{ Over 35} \\
\hline & $\begin{array}{l}\text { Top } 10 \text { weighted } \\
\text { index }(\mathrm{N}=6579)\end{array}$ & $\begin{array}{l}\text { All } \\
(N=21136)\end{array}$ & $\begin{array}{l}\text { Top } 10 \text { weighted } \\
\text { index }(\mathrm{N}=4278)\end{array}$ & $\begin{array}{l}\text { All } \\
(\mathrm{N}=7312)\end{array}$ \\
\hline 5 year & $2479(218)$ & $1695(104)$ & $1586(209)$ & $1347(151)$ \\
\hline Rate ratio $(95 \% \mathrm{CI})$ & \multicolumn{2}{|c|}{$1.46(1.22$ to 1.76$) ; p=0.002$} & \multicolumn{2}{|c|}{$1.18(0.87$ to 1.6$) ; \mathrm{p}=0.3$} \\
\hline 10 year & $3875(326)$ & $2728(156)$ & $2365(275)$ & $2138(224)$ \\
\hline Rate ratio $(95 \% \mathrm{CI})$ & \multicolumn{2}{|c|}{$1.42(1.23$ to 1.64$) ; p<0.001$} & \multicolumn{2}{|c|}{$1.11(0.86$ to 1.42$) ; p=0.42$} \\
\hline
\end{tabular}

Conclusion TB risk among immigrants newly registering with a GP is heterogeneous. Indices for risk stratification are identifiable that may improve cost-effectiveness of targeted screening.

\section{P59 DIFFERING PATTERNS OF NEW IMMIGRANT GP REGISTRATION AMONG ETHNIC SUBGROUPS DETERMINE THE IMPORTANCE OF ADDITIONAL STRATEGIES FOR MODELS OF NEW IMMIGRANT SCREENING}

doi:10.1136/thoraxjnl-2011-201054c.59

R K Panchal, P Haldar, G Woltmann. Glenfield Hospital, University Hospitals of Leicester, Institute for Lung Health (ILH), Leicester, UK

Introduction New immigrant GP registration databases maybe an important tool for identifying recent immigrants to the UK at high risk of latent infection with $M$ tuberculosis (LTBI), who may benefit from screening and treatment to prevent tuberculosis (TB). However, effectiveness of this strategy is determined by the proportion of immigrants that register and the time after UK entry that registration occurs.

Aims To evaluate whether differences exist in the pattern of GP registration onto the new immigrant registration database for Leicestershire (Flag-4), between immigrants stratified by age group $(<16,16-35$ or $=36$ years) and ethnicity (Indian sub-continent [ISC] or Black African).

Methods A retrospective analysis was performed of all immigrants entering the UK after 1999 that were Flag-4 registered between 2000 and $2010(\mathrm{~N}=29186)$ and collated with data for all TB notifications over the same period $(\mathrm{N}=884)$. Comparisons were made between immigrants developing TB and staying healthy; and between TB cases occurring in foreign born persons captured or missed by the new immigrant database. Among captured cases, the proportion with a notification date at least 12 months after UK entry and 4 months after GP registration were considered preventable.

Results There was a significant and inverse relationship for the proportions of cases captured and missed by the Flag- 4 system in black Africans and ISC immigrants (Abstract P59 table 1, p <0.001) The higher proportion of missed cases in black Africans was evident for both adult age groups but not children. Among registered immigrants, those developing TB had a significantly longer delay to registration (mean difference [95\% CI] 420 [259 to 580] days, $\mathrm{p}<0.001$ ). Compared with age stratified ISC immigrants, time to registration was significantly longer for black Africans aged 16-35 years (mean difference 832 days, $p<0.001$ ). However, the proportion of preventable cases in registered immigrants was similar between ISC and black Africans (83.3\% and 90.2\%).

\section{Abstract P59 Table 1}

\begin{tabular}{llll}
\hline \multirow{2}{*}{ Ethnicity } & \multicolumn{4}{l}{ TB cases / N (\% of total) } \\
\cline { 2 - 4 } & All cases & Captured & Missed \\
\hline Indian subcontinent & $490(55.4)$ & $294(62.6)$ & $196(47.3)$ \\
Black African & $\mathbf{2 2 2 ( 2 5 . 1 )}$ & $\mathbf{9 2}(\mathbf{1 9 . 6 )}$ & $\mathbf{1 3 0 ( 3 1 . 4 )}$ \\
\hline
\end{tabular}

Conclusions Strategies to encourage early registration by new immigrants with a GP may improve utility of this resource for screening. However, greater emphasis on complementary strategies, including engagement of third sector organisations is needed, particularly for identifying black African immigrants at risk of TB.

\section{P60 SIMPLE MEASURES TO IMPROVE TB CONTROL: APPLYING THE COHORT REVIEW PROCESS IN LONDON}

doi:10.1136/thoraxjnl-2011-201054c.60

${ }^{1} \mathrm{~J}$ White, ${ }^{2} \mathrm{C}$ Anderson, ${ }^{1} \mathrm{~S}$ Dart, ${ }^{2} \mathrm{~S}$ Tamne, ${ }^{1} \mathrm{~J}$ deKoningh, ${ }^{1} \mathrm{~S}$ Hemming, ${ }^{2} \mathrm{~S}$ Anderson, ${ }^{2}$ A Abubakar, ${ }^{1} \mathrm{M}$ Lipman. ${ }^{1}$ Royal Free Hospital, London, UK; ${ }^{2}$ Health Protection Agency, London, UK

Despite much recent effort, there has been little change in national rates of tuberculosis (TB). Outside of the UK, the brief, structured review of the management, contact investigation and outcome of each TB case during their treatment (cohort review, CR) has improved TB control. North Central London (NCL) TB Service has piloted this approach. To date, 525 subjects with active TB have been discussed at four cohort reviews. Each "cohort" of patients were reviewed 6-9 months from start of treatment. A single case is usually reviewed within 3 min. Here we compare key outcomes relating to case management and contact tracing between an NCL TB population notified and treated prior to CR (Quarter 3 2009, $\mathrm{n}=158$ ) and following CR implementation (Quarter 3, 2010, 1 year from start, $\mathrm{n}=125)$. 